\title{
Metrical Structure in Planning the Production of Spoken Words
}

\author{
Ardi Roelofs and Antje S. Meyer \\ Max Planck Institute for Psycholinguistics
}

\begin{abstract}
According to most models of speech production, the planning of spoken words involves the independent retrieval of segments and metrical frames followed by segment-to-frame association. In some models, the metrical frame includes a specification of the number and ordering of consonants and vowels, but in the word-form encoding by activation and verification (WEAVER) model (A. Roelofs, 1997), the frame specifies only the stress pattern across syllables. In 6 implicit priming experiments, on each trial, participants produced 1 word out of a small set as quickly as possible. In homogeneous sets, the response words shared word-initial segments, whereas in heterogeneous sets, they did not. Priming effects from shared segments depended on all response words having the same number of syllables and stress pattern, but not on their having the same number of consonants and vowels. No priming occurred when the response words had only the same metrical frame but shared no segments. Computer simulations demonstrated that WEAVER accounts for the findings.
\end{abstract}

Most theories of word production assume that the phonological representations constructed in planning utterances include separate representations of the segmental content of words and of their metrical properties, such as their syllable structure and stress pattern. This view is compatible with current linguistic theory, which allocates segmental and metrical information on separate representational tiers (e.g., Goldsmith, 1990; Kenstowicz, 1994). In addition, psycholinguistic models often contend that during speech planning, the metrical and segmental tiers are first retrieved, or generated, independently of each other and later combined (see Levelt, 1989, for an overview).

Most of the evidence for this view comes from analyses of speech errors. The argument runs roughly as follows (see, for instance, Meyer, 1992, for a more extensive discussion). Speakers often commit sound errors, in which the intended and the actual utterance differ in a speech fragment smaller than a complete morpheme. Usually, these fragments correspond to individual segments or, less often, to clusters of two adjacent segments. This shows that, during speech planning, stored form representations are decomposed into their segments. Misplaced segments typically move from their target positions to corresponding positions in new syllables, for instance from one syllable onset (the prevocalic part of a

Ardi Roelofs and Antje S. Meyer, Max Planck Institute for Psycholinguistics, Nijmegen, The Netherlands.

We are indebted to Pim Levelt for discussion and to Maarten van Casteren for his help in preparing and running the experiments. We thank Gary Dell, Stephanie Shattuck-Hufnagel, and Joseph Stemberger for their helpful comments on a version of this article.

Correspondence concerning this article should be addressed to Ardi Roelofs, who is now at the Department of Psychology, University of Exeter, Washington Singer Laboratories, Perry Road, Exeter EX4 4QG United Kingdom, or to Antje S. Meyer, Max Planck Institute for Psycholinguistics, P.O. Box 310, 6500 AH Nijmegen, The Netherlands. Electronic mail may be sent to Ardi Roelofs at a.roelofs@ex.ac.uk or to Antje S. Meyer at asmeyer@mpi.nl. syllable) to another syllable onset, as in meal mystery instead of real mystery, or from one nucleus (the vocalic part of a syllable) to another nucleus, as in fool the pill instead of fill the pool. ${ }^{1}$ Thus, the syllable structure of the utterance governs which positions misplaced segments may take. Syllable structure is often represented as a frame with positions to which segments are associated. During wordform generation, speakers retrieve segments and syllable frames and then associate the segments to positions of the frames.

Thus, most models of word-form generation make two important claims about the metrical representation: Namely, first, that it is retrieved independently of the segmental representation; and, second, that it captures (possibly among other things) syllable-internal positions. The syllableposition constraint on sound errors described above is usually considered to support both of these claims. However, as Shattuck-Hufnagel $(1987,1992)$ and Garrett $(1975,1980)$ have pointed out, most of the evidence for this constraintmore than $80 \%$ of the relevant cases in the English corpora that have been analyzed-stems from errors involving word-initial consonants. Thus, English-word onset consonants are particularly error-prone and tend to interact with each other rather than with word-internal segments; this explains most of the evidence usually taken to support the syllable-position constraint. Consonantal errors not involving word onsets are too rare to be analyzed for adherence to a positional constraint. Vowels show a very strong tendency to interact with each other rather than with consonants. This could be due to a syllable-position constraint, but it could also be due to the general tendency of segments to interact with phonologically similar rather than dissimilar segments (Shattuck-Hufnagel, 1986; Shattuck-Hufnagel \& Klatt, 1979). Thus, the constraints on segment movements observed in English speech errors do not provide unambiguous support for a representation of syllable-internal structure. Stronger

\footnotetext{
${ }^{1}$ All speech errors stem from Fromkin's (1973) corpus.
} 
evidence comes from Berg's (1991) analyses of a Spanish error corpus, collected by García-Albea, del Viso, and Igoa (1989): For the Spanish sound errors, a clear syllableposition constraint but no word-onset effect was observed.

Stemberger $(1984,1990)$ looked for evidence for frames of a slightly different type, namely frames encoding the consonant-vowel (CV) structure of the utterance. Such a representation has been proposed in phonological theory (e.g., Clements \& Keyser, 1983; Goldsmith, 1990; McCarthy, 1981) as an interface between the syllabic and the segmental representations. Each syllable and segment are associated to one or more $\mathrm{CV}$ positions. The $\mathrm{CV}$ tier captures the number and ordering of vocalic and consonantal elements and their length; short segments associate to one position and long ones to two positions of the CV tier. The representations of the English words bet and bean are given in the following graphic example. Short vowels are associated to one position and long vowels to two positions of the CV tier:

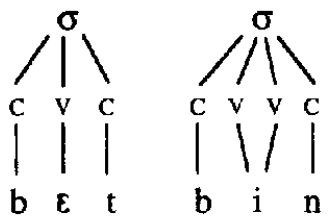

Stemberger (1984) examined errors involving segments differing in length. If misordered segments typically acquire the length of the segments they replace, length can be represented independently of segmental content in terms of the number of positions on the CV tier. Stemberger's (1984) analyses of small corpora of German and Swedish errors supported this view, but his analysis of an English corpus did not. In another study, Stemberger (1990) found that additions to onset consonants (as in steel fleet instead of steel feet) were more likely when the source word (steel in the example) began with a cluster than when it began with a single consonant. Thus, there was a tendency toward increased similarity of the CV structures of the interacting words. In addition, the chance of an onset interaction was higher when target and source word had the same number of coda consonants (i.e., consonants following the vowel) than when they differed in the number of coda consonants. Errors such as life can be a lame (instead of game), in which the interacting words each have one coda consonant, were slightly more likely than errors such as hinch hit (instead of pinch hit), in which the interacting words differ in the number of coda consonants. However, the chance of onset interaction errors did not differ for words with matching or different structures of the syllable nuclei (V vs. VV). In short, Stemberger's evidence is suggestive, but it does not offer very strong support for the assumption that the CV structure is represented independently of the segmental structure.

Experimental evidence concerning the CV structure is scarce. In two priming experiments carried out in Dutch, Meijer $(1994,1996)$ showed that word production was facilitated by primes with the same $\mathrm{CV}$ structure as the targets relative to primes differing in the number of consonants. However, in another experiment (Meijer, 1994), this effect was not replicated. In a fourth experiment, in which primes and targets had matching or different structures of the nucleus (V or VV), no priming effect from shared CV structure was obtained.

Sevald, Dell, and Cole (1995) used a repeated pronunciation task to study the representation of CV structure in English. They asked speakers to produce pairs of one monosyllabic and one disyllabic pseudoword as often as they could within $4 \mathrm{~s}$. They found that more sequences were produced within the response period when the monosyllable had the same CV structure as the first syllable of the disyllable (as in kul par-fen; the hyphen marks the syllable boundary) than when this was not the case (as in kult par-fen; the number of segments per sequence was controlled across items). On the basis of these results, Sevald et al. argued for abstract syllable frames, which are sequences of consonantal and vocalic positions (see also Dell, 1988).

Levelt (1992; see also Levelt \& Wheeldon, 1994) has argued for metrical representations that do not capture syllable-internal structure but only the number of syllables and the location of primary stress. If the creation of word forms includes the retrieval of such metrical representations, one might expect that occasionally an incorrect metrical representation is retrieved, which should result in a stress error (e.g., simiLARly, stressed on the third syllable). Stress errors indeed occur, but the erroneous stress pattern (i.e., the assignment of primary stress to one of the word's syllables) is almost always that of a morphologically related word. Therefore, Cutler $(1980 a, 1980 \mathrm{~b})$ has argued that these errors most likely arise during morphological encoding. Sometimes errors occur in which a stressed and an unstressed vowel interact with each other. Listeners then typically have the impression that the stress pattern of the intended utterance is maintained (e.g., Shattuck-Hufnagel, 1986). This suggests that the segmental content is represented separately from a metrical structure capturing the stress pattern and that only the segmental information is affected by the error. However, such errors are rare, and there is no objective evidence that constancy of stress pattern is indeed produced by the speakers rather than arising in the listeners' ears (or minds).

In summary, almost all models of word-form generation assume that speakers retrieve frames to which positions segments are linked during a later processing stage (for exceptions see Béland, Caplan, \& Nespoulous, 1990; Dell, Juliano, \& Govindjee, 1993). Given the central role these frames play in word-form generation, it is surprising to note how little experimental research has been carried out to test whether speakers indeed retrieve such frames and what the properties of these frames are. In the present study, we tested two hypotheses: that speakers retrieve metrical structures consisting of syllables marked for stress (as proposed by Levelt, 1992) and that they retrieve frames consisting of ordered consonantal and vocalic positions (as proposed by Dell, 1988, and Stemberger, 1984, 1990). These hypotheses obviously do not exclude each other. Our experiments were 
specifically designed to test whether stress and the parsing of word forms into syllables or into consonantal and vocalic positions or both were represented separately from segmental content. We did not intend to test whether these properties of word forms are represented at all. Even if, for instance, we do not obtain any evidence for the existence of a separate CV tier, it is still possible that the consonantal or vocalic character of segments is coded as part of the segmental content.

The remainder of this article is organized as follows. In the next section, we describe the word-form encoding by activation and verification (WEAVER) model of Dutch word-form encoding proposed by Roelofs (1994, 1996, 1997), which realizes Levelt's (1992) proposal concerning the nature of the metrical representation in a specific way. Next, we explain the paradigm used in the present study, which is the implicit form-priming paradigm developed by Meyer $(1990,1991)$. We then report six experiments, which were carried out with native speakers of Dutch, and tested predictions about the metrical structure that were derived from WEAVER. These experiments served not only the general purpose of gaining evidence about the nature of metrical representations, but also served to test WEAVER. Finally, we show that WEAVER simulates the key findings and discuss the implications of the results for theories of spoken word production.

\section{The WEAVER Model of Form Encoding}

Three major types of processes underlie speaking: conceptualization, formulation, and articulation (e.g., Caplan, 1992; Garrett, 1975; Kempen \& Hoenkamp, 1987; Levelt, 1989). Conceptualization processes generate messages, which are conceptual structures to be verbally expressed. Messages specify lexical concepts and their relationships. Formulation processes take the message as input, access appropriate words, and build a syntactic and a morphophonological structure for the utterance. On the basis of the latter structure, articulatory programs are retrieved and finally executed.

Lexical access to a single word consists of two major steps: lemma retrieval and word-form encoding (e.g., Butterworth, 1989; Dell, 1986; Garrett, 1975; Kempen \& Hoenkamp, 1987; Kempen \& Huijbers, 1983; Levelt, 1989, 1992; Meyer, 1996; Roelofs, 1992a, 1992b, 1993, 1996). These two steps take place during the formulation stages of syntactic and morphophonological encoding, respectively. During lemma retrieval, a lexical concept is used to retrieve the lemma of a corresponding word from memory. Lemmas represent the syntactic properties of words. For example, the lemma of the Dutch word water (English water) specifies that it is a noun and that its grammatical gender is neuter. The lemma lachen (to laugh) specifies that it is a verb and that it is intransitive. Lemma retrieval makes these properties available for syntactic encoding.

Word-form encoding comprises three major steps: morphological, phonological, and phonetic encoding (cf. Dell, 1986; Levelt, 1989, 1992; see Figure 1). The morphological encoder takes the lemma and often diacritic features (such as
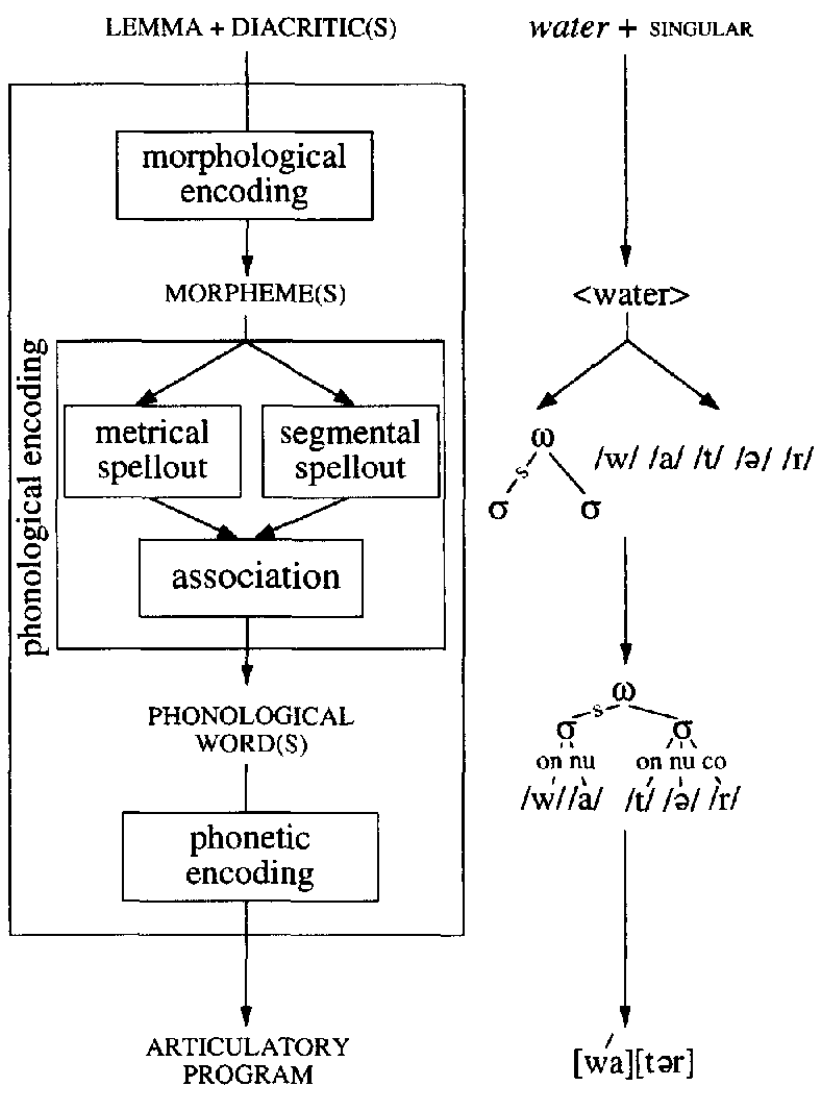

Figure 1. Stages of word-form encoding and the representations that are computed or recovered from long-term memory. $\omega=$ phonological word; $\sigma=$ syllable; $\mathrm{s}=$ stressed; on = onset; $\mathrm{nu}=$ nucleus; $\mathrm{co}=$ coda.

singular or plural) as input and produces one or more morphemes, for instance, a noun stem and a plural affix. On the basis of these morphemes, the phonological encoder produces a phonological representation. Finally, the phonetic encoder generates a more detailed and contextdependent form representation, which specifies the articulatory commands to be carried out.

The WEAVER model realizes this global view of wordform encoding, which is shared by many models, in a specific manner. WEAVER assumes that the mental lexicon is a network of nodes and links that is accessed by spreading activation (Roelofs, 1992a, 1992b, 1993, 1994, 1996, 1997). The lexical network consists of three strata: a conceptual stratum with lexical-concept nodes and links (e.g., WATER(X), LAKE(X), IS-A); a syntactic stratum with lemma nodes (e.g., water), nodes and links for syntactic properties (e.g., lexical category: noun) and slots and fillers for diacritics (e.g., has-number: singular), and a word-form stratum with metrical, morpheme, segment, and syllableprogram nodes and links. The word-form stratum is connected to a phonetic syllabary, which is a store of readymade motor programs for syllables (Levelt, 1989, 1992; Levelt \& Wheeldon, 1994).

Figure 2 illustrates the memory representation of Dutch 


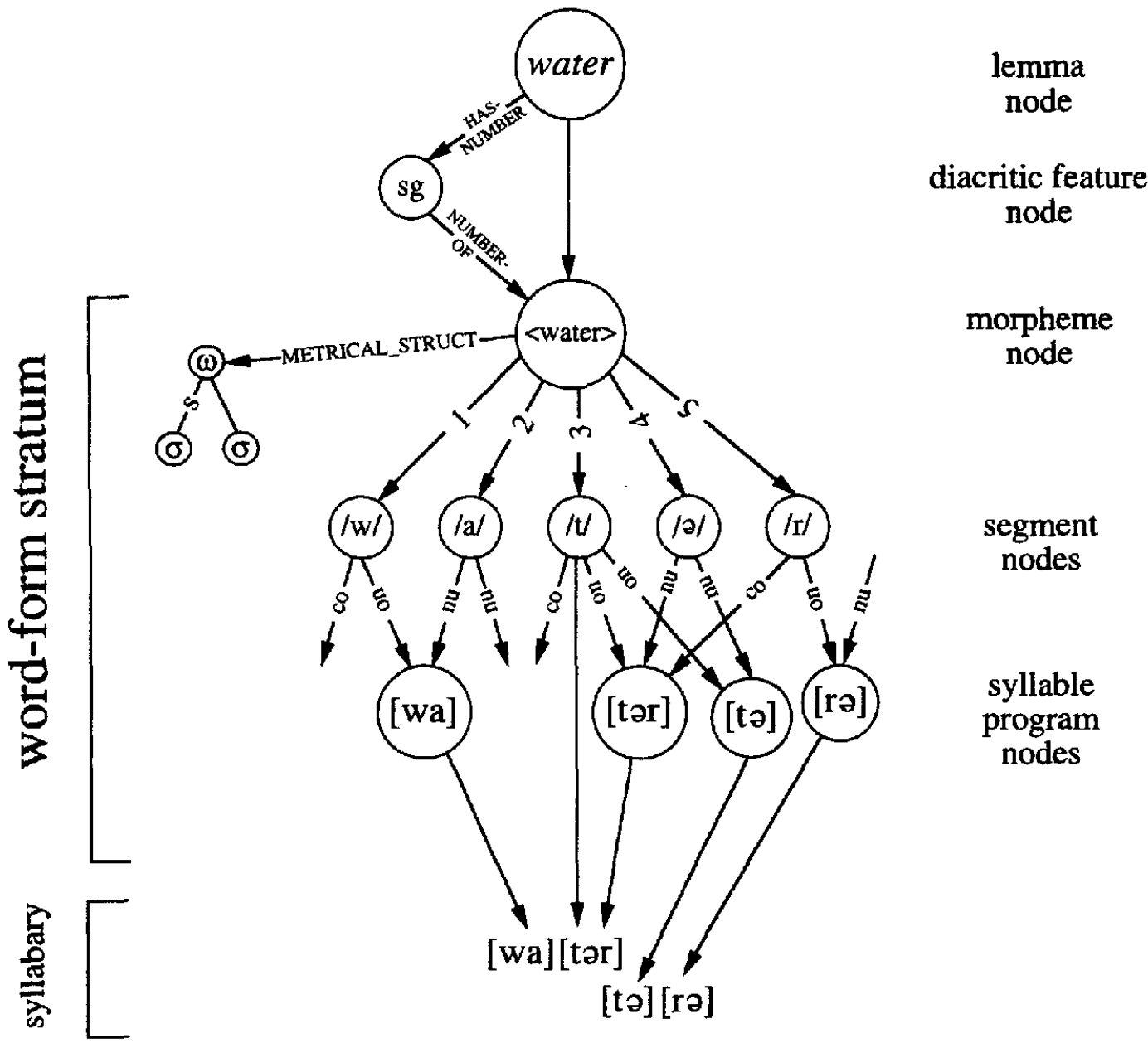

Figure 2. Illustration of memory representations in the word-form encoding by activation and verification model (WEAVER; Roelofs, 1994, 1996, 1997). Fragment of the lexical network representing the word form of water. $\mathrm{sg}=$ singular, $\omega=$ phonological word; $\sigma=$ syllable; $s=$ stressed; on $=$ onset; nu $=$ nucleus; co $=$ coda; struct $=$ structure.

water in WEAVER. The nonmetrical part of the form network consists of three layers of nodes: morpheme nodes, segment nodes, and syllable-program nodes. Morpheme nodes stand for stems and affixes. They are connected to lemmas and diacritics. For instance, the stem (water) is connected to the lemma of water and the diacritic singular. A morpheme node points to its metrical structure and the segments that constitute its phonological form. The metrical structure is an abstract grouping of syllables $(\sigma)$ into a phonological word $(\omega)^{2}$ The syllable carrying primary stress (called stressed syllable hereafter) is marked (by " $\mathrm{s}$ " on the link to the syllable). Note that in the stored phonological representations, segments are not yet linked to syllables and the CV pattern is not specified. The links between morpheme and segment nodes indicate the serial positions of the segments within the morpheme. Possible syllable positions (onset, nucleus, coda) of the segments are specified by the links between segment nodes and syllable-program nodes. For example, the network specifies that $/ r /$ is the coda of [tər] and the onset of [ro].
Information is retrieved from the network through spreading of activation. Activation spreads through the network in a forward fashion. Each node sends a proportion of its activation to the nodes it is connected to. There is also spontaneous decay of activation. The form encoders follow simple selection rules. Attached to the nodes in the network, there are production rules (i.e., condition-action pairs) that select nodes if they are appropriately linked to the target nodes one level up. A production rule is triggered when the activation levels of its nodes exceed threshold. Productions may operate in parallel.

Word-form encoding starts when a morpheme node receives activation from a selected lemma. The morphological encoder selects the morpheme nodes that are linked to the selected lemma and its diacritics. Thus, the stem (water)

\footnotetext{
${ }^{2}$ A phonological word is a phonological unit that must include at least one, but can include several, lexical words. For instance, in $I$ took it, the last two words may be realized as one phonological word, $\left((\mathrm{tu})_{\sigma}(\mathrm{kIt})_{\sigma}\right)_{\omega}$.
} 
is selected for the lemma water and the diacritic singular. The phonological encoder then selects the segments and the metrical structures that are linked to the selected morpheme nodes. Next, the segments and metrical structure are input to a syllabification process that associates the segments to the syllable nodes in the metrical structure. An important feature of the association process is that it proceeds strictly sequentially, from the segment whose link is labeled first to the one labeled second and so forth. The primary empirical motivation for this assumption came from experiments by Meyer $(1990,1991)$, which are described in the next section. In associating the segments to the metrical structure, syllable positions (onset, nucleus, coda) are assigned to the segments following the syllabification rules of the language. Important syllabification rules are that each vowel and diphthong is to be associated to a different syllable and that intervocalic consonants are to be treated as syllable onsets whenever possible, that is, unless phonotactically illegal onset clusters arise. The latter rule is the maximal onset principle of syllabification (e.g., Goldsmith, 1990). For example, in Dutch borstel (brush) will be syllabified as (bor) $)_{\sigma}(\mathrm{stol})_{\sigma}$ because /st/ is a legal syllable onset, but /rst/ is not. In the encoding of water, the $/ \mathrm{w} /$ is made syllable onset and the $/ \mathrm{a} /$ nucleus of the first syllable, and the / $t /$ onset, the /a/ nucleus, and the $/ \mathrm{r} /$ coda of the second syllable.

In polymorphemic words and connected speech, adjacent morphemes or words may be combined into new phonological words, which may change the syllable positions of segments (Booij, 1995; Levelt, 1989, 1992). For example, /r/ is the coda of the second syllable of singular water, but it is the onset of the third syllable of plural wateren. In WEAVER, the association of segments to metrical structures accounts for syllabification across morpheme and word boundaries. For example, WEAVER may combine the structures of the stem (water) and the affix (en) for the plural wateren, and then, following the maximal onset principle, $/ \mathrm{r} /$ will be made onset of the third syllable instead of coda of the second syllable, yielding $(\mathrm{wa})_{\sigma}(\mathrm{t} \partial)_{\sigma}(\mathrm{r} \partial)_{\sigma}$.

The phonetic encoder selects the syllable-program nodes that have labeled links to segments that correspond to the syllable positions assigned to the segments during the preceding processing step. For example, [tor] is selected for the second syllable of water because the link between [tor] and $/ t /$ is labeled onset, the link between [tər] and $/ \partial /$ nucleus, and the link between [tər] and $/ r /$ coda. Finally, the phonetic encoder addresses the syllable programs in the syllabary, thereby making them available to the articulators for the control of speech movements. The phonetic encoder uses the metrical representation to set parameters for loudness, pitch, and duration. The resulting hierarchical speech plan governs articulation (e.g., Rosenbaum, Kenny, \& Derr, 1983).

WEAVER provides for a suspension-resumption mechanism that supports incremental generation of phonetic plans. Incremental production means that encoding processes can be triggered by a fragment of their characteristic input (Levelt, 1989). For example, syllabification of a word can start as soon as the first few segments and the metrical structure are available. The resulting partial representation can be buffered until the missing segments are available and syllabification can continue. Thus, when given partial information, computations are completed as far as possible, after which they are put on hold. When given further information, the encoding processes continue from where they stopped. As is shown in the next section, this suspension-resumption mechanism plays a crucial role in explaining the results of implicit form-priming experiments. A full account of the theoretical and empirical motivation of the specific design characteristics of WEAVER, a comparison to other models of word-form generation, and applications of the model to classical findings from speech-error analyses and speechproduction experiments can be found in Roelofs (1994, 1996, 1997). Roelofs (in press) discusses the generation of complex verb forms.

\section{The Implicit Form-Priming Paradigm}

The present study used the implicit form-priming paradigm. In Meyer's $(1990,1991)$ implicit form-priming experiments, native speakers of Dutch first learned small sets of Dutch word pairs such as meer-water, snoep-wafel, and auto-wagen (English lake-water, sweet-waffle, and autocar). During the following test phase, they had to produce the second word of a pair (e.g., water) upon visual presentation on a computer screen of the first word (meer), called the prompt. On each trial, one of the prompts was presented. The order of prompts was random. The production latency (i.e., the interval between prompt onset and speech onset) was the main dependent variable. Each experiment comprised two types of sets, called homogeneous and heterogeneous sets. In a homogeneous set, the response words shared part of their form, for example the first syllable (water, wafel, wagen) or the second syllable (water, boter [butter], meter [meter]). In the heterogeneous sets, the response words were unrelated in word form. The heterogeneous sets were created by regrouping the pairs from the homogeneous sets. Therefore, each word pair was tested both under the homogeneous and the heterogeneous condition, and all uncontrolled item effects were kept constant across these conditions. A priming effect was said to have occurred if the production latencies in the homogeneous condition were shorter than those in the heterogeneous condition. Meyer $(1990,1991)$ found such a priming effect only when the response words in homogeneous sets shared one or more word-initial segments but not when they shared word-final segments. For example, a priming effect was obtained for the begin-related homogeneous set that included water, wafel, and wagen but not for the end-related homogeneous set that included water, boter, and meter. The strength of the priming effect increased with the number of shared word-initial segments.

According to WEAVER, facilitation arises when participants prepare and buffer partial phonological representations of the response words before prompt presentation. This preparation entails the association of segments to syllables. The confinement of the facilitatory effect to begin-related homogeneous sets reflects the suspension-resumption mechanism that underlies the incremental planning of utterances. Assume that the set of response words (response set, 
hereinafter) consists of water, wafel, and wagen. Before the beginning of a trial, the morphological encoder can do nothing, but the phonological encoder can construct the first phonological syllable (wa) ${ }_{\sigma}$, and the phonetic encoder can recover the first phonetic syllable [wa]. As soon as a prompt (e.g., meer) is given, the morphological encoder will retrieve the associated target morpheme (for meer this is (water)). Segmental spell-out makes all segments of this morpheme available, including those of the second syllable, and the phonological and phonetic encoders can begin to work on the second syllable. In the heterogeneous condition (wafel, boter, etc.), nothing can be prepared before prompt presentation. There will be no morphological, phonological, or phonetic encoding. In the end-related homogeneous condition (water, boter, meter) nothing can be done either. Although the segments of the second syllable are known, the phonological form cannot be computed because the missing segments precede the suspension point. In WEAVER, this means that after prompt presentation, syllabification must restart from the first segment of the word, which amounts to restarting the whole process. Thus, a facilitatory effect for the homogeneous relative to the heterogeneous condition will only be obtained for begin-related response words. Computer simulations of Meyer's (1990) experiments can be found in studies by Roelofs $(1994,1997)$.

\section{Overview of Experiments 1, 2, and 3}

As explained above, according to WEAVER facilitation in implicit form-priming experiments arises when participants prepare for the response words before prompt presentation by associating one or more segments to syllables. Therefore, WEAVER predicts that facilitation should be obtained only if the response words in homogeneous sets share segments and have the same metrical structure. If metrical structures are stored and must be retrieved for advance planning, preparation should be possible only if the number of syllables and the stress pattern are the same throughout the response set but not if they are variable. By contrast, if metrical structures are not involved in advance planning or if they are computed on-line on the basis of the retrieved segments (cf. Béland et al., 1990), preparation should be possible even if the number of syllables and the stress pattern of the responses in a set are variable. Experiments 1 and 2 tested these predictions by comparing the effect of segmental overlap for response sets that all had the same metrical structure with that for sets comprising response words differing in metrical structure.

WEAVER's metrical structures do not capture the CV structure of words. Hence, preparation for shared segments should be possible regardless of whether the response words have the same or different $\mathrm{CV}$ structures, provided that the number of syllables and stress pattern are constant. Experiment 3 tested this prediction.

\section{Experiment 1}

The first experiment compared the effect of word-initial segmental overlap for response sets including only disyl- labic words such as manier (manner), matras (mattress), and makreel (mackerel) with that for sets comprising one response word each with two, three, and four syllables such as majoor (major), materie (matter), and malaria (malaria). Primary stress was always on the second syllable counted from word onset. WEAVER predicts that a facilitatory effect of segmental overlap should be obtained only when all response words of a set have the same number of syllables. Other theories (e.g., Béland et al., 1990) predict that facilitation should be obtained regardless of whether the words in a set have the same number of syllables or differ in the number of syllables.

\section{Method}

Participants. All experiments were conducted with paid participants from the pool of the Max Planck Institute. All participants were young adults (ranging in age from 18 to 30 years) and native speakers of Dutch. Each person only took part in one experiment. Experiment 1 was carried out with 12 participants.

Materials and design. The materials for all experiments were obtained from the Dutch part of the Centre for Lexical Information (CELEX) lexical database (Baayen, Piepenbrock, \& van Rijn, 1993). All prompts and response words were nouns because suitable items were easiest to find in this word class. The materials for Experiment 1 consisted of 4 practice sets and 12 experimental sets of 3 prompt-response word pairs each (see Table 1). Each set was tested in a separate block of trials. In 6 experimental sets (the homogeneous sets), the response words shared the first syllable, and in the remaining 6 sets (the heterogeneous sets), they were unrelated in form. Thus, in the homogeneous condition, each response word was tested together with other response words with the same first syllable, whereas in the heterogeneous condition, the response words tested together in a block did not share a syllable. Following Meyer (1990), the first independent variable-homogeneous versus heterogeneous sets-is called context. The same prompt-response word pairs were tested in the homogeneous and heterogeneous condition; only their combinations into sets differed. The shared syllables in the homogeneous sets were $/ \mathrm{ma} /, \mathrm{br} /$, and /si/. Each of these syllables was used in two homogeneous sets. The second independent variable, which had three levels $(/ \mathrm{ma} /, / \mathrm{b} /$, and /si/), is called fragment.

In three homogeneous and in three heterogeneous sets including the same response words, all response words were disyllabic. In three other homogeneous sets and in the corresponding heterogeneous sets, the response words varied in length. Each of these sets included one response word with two, three, and four syllables. The third independent variable, which had two levels (constant vs. variable), is called number of syllables.

Each response word was coupled with a prompt that we considered a strong and unambiguous retrieval cue for the corresponding target. For instance, the target makreel (English mackerel) was coupled with the prompt vis (fish), and the target citroen (lemon) with the prompt appel (apple). Prompts within a set differed by no more than three characters in length.

Each participant was tested once on each set. The order of the sets was rotated across participants in the following way. Six participants (Groups $A$ and $B$ ) were first tested on the sets with variable, and then on those with constant, number of syllables. For the remaining 6 participants (Groups $C$ and D), the order of testing constant and variable sets was reversed. For participants of Groups $A$ and C, Blocks 1-3 and Blocks 7-9 were homogeneous, and the remaining blocks were heterogeneous. For participants of Groups 
Table 1

Response Sets of Experiment 1

\begin{tabular}{|c|c|c|}
\hline No. of syllables & Context & Set \\
\hline Constant & Homogeneous & 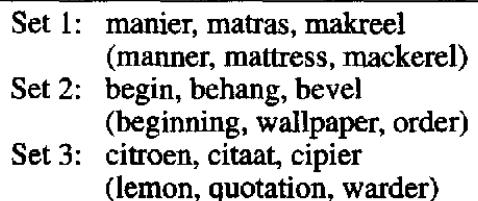 \\
\hline & Heterogeneous & $\begin{array}{l}\text { Set 4: matras, citroen, bevel } \\
\text { Set 5: cipier, behang, manier } \\
\text { Set 6: begin, makreel, citaat }\end{array}$ \\
\hline Variable & Homogeneous & $\begin{array}{ll}\text { Set 7: } & \begin{array}{l}\text { majoor, materie, malaria } \\
\text { (major, matter, malaria) }\end{array} \\
\text { Set 8: } & \begin{array}{l}\text { betekenis, beroep, begeerte } \\
\text { (meaning, occupation, desire) }\end{array} \\
\text { Set 9: } & \begin{array}{l}\text { sirene, silicium, sigaar } \\
\text { (siren, silicon, cigar) }\end{array}\end{array}$ \\
\hline & Heterogeneous & $\begin{array}{l}\text { Set 10: sigaar, betekenis, materie } \\
\text { Set 11: begeerte, majoor, silicium } \\
\text { Set 12: malaria, sirene, beroep }\end{array}$ \\
\hline
\end{tabular}

Note. English translations are given in parentheses.

$\mathrm{B}$ and $\mathrm{D}$, the order of homogeneous and heterogeneous sets was reversed. Thus, the same combination of context and number of syllables was tested in three successive blocks-one quarter-of the experimental session. A different order of the three sets within a quarter was used for each participant of a group, such that each set was tested once as the first, second, and third set within the quarter.

Each of the three prompt-response word pairs of a set was tested six times within each block. In all experiments, the order of testing the word pairs was random, except that immediate repetitions of pairs were excluded. A different order was used for each block and each participant.

Procedure and apparatus. The participants were tested individually. They were seated in a quiet room in front of a computer screen (NEC Multisync30) and a microphone (Sennheisser ME40). After the participant had read the instructions, 4 practice blocks (with the same structure as the experimental blocks but with different items) were administered, followed by the 12 experimental blocks. In the learning phase before each block, the three word pairs of a set were presented on the screen. As soon as the participant indicated having studied the pairs sufficiently, the experimenter started the test phase. The structure of a trial was as follows. First, the participant saw a warning signal (an asterisk) for $500 \mathrm{~ms}$. Next, the screen was cleared for $500 \mathrm{~ms}$, followed by the display of the prompt for $1,500 \mathrm{~ms}$. The asterisk and prompt were presented in white on a black background. Finally, before the start of the next trial there was a blank interval of $500 \mathrm{~ms}$. Thus, the total duration of a trial was $3 \mathrm{~s}$. The experiment was controlled by a Hermac $386 \mathrm{SX}$ computer. This procedure and apparatus were used in all experiments.

Response coding. After each trial, the experimenter coded the response for errors. Experimental sessions were recorded on audiotape by a Sony DTC55 DAT recorder. The recordings contained the participants' speech and tones indicating the onset of the prompt $(1.0 \mathrm{kHz})$ and the moment when the voice key was triggered $(2.5 \mathrm{kHz})$. The experimenter heard these tones during the experiment through closed headphones. The recordings were consulted after the experiment whenever the experimenter was uncertain whether a response was correct. Four types of incorrect responses were distinguished: wrong response words; disfluencies (stuttering, within-utterance pauses, repairs); triggering of the voice key by nonspeech sounds (noise in the environment or smacking sounds participants produced with the lips or tongue); and failures to respond within 1,500 ms after prompt presentation.

\section{Results and Discussion}

For all experiments, separate by-participant and by-item analyses of variance (ANOVAs) were performed on the production latencies for correct responses and on the error rates. We report all effects that reached the $p<.05$ level of significance in one or both analyses. Because none of the main effects or interactions was significant for error rates, error data is not mentioned hereafter.

Table 2 gives the mean production latencies and the error percentages for Experiment 1 . The data were analyzed with the crossed variables context (homogeneous vs. heterogeneous), number of syllables (constant vs. variable), and fragment $(/ \mathrm{ma} /, / \mathrm{b} /$, or $/ \mathrm{si})$ ). All variables were tested within participants. Context was tested within items, and the other two variables were tested between items. As shown in Table 2 , a facilitatory effect from segmental overlap was obtained for constant but not for variable sets. The Context $\times$ Number of Syllables interaction was significant, $F_{1}(1,11)=9.04$, $M S E=1,260, p<.012 ; F_{2}(1,12)=6.26, M S E=455, p<$ .028 . The main effect of context was significant by items but

Table 2

Mean Production Latencies (in Milliseconds), Error Percentages, and Priming Effects (Diff.) for Experiment 1

\begin{tabular}{|c|c|c|c|c|c|c|}
\hline \multirow{3}{*}{$\begin{array}{c}\text { No. of } \\
\text { syllables }\end{array}$} & \multicolumn{4}{|c|}{ Context } & \multirow{2}{*}{\multicolumn{2}{|c|}{ Diff. }} \\
\hline & \multicolumn{2}{|c|}{ Homogeneous } & \multicolumn{2}{|c|}{ Heterogeneous } & & \\
\hline & $M$ & $\%$ error & $M$ & $\%$ error & $M$ & $\%$ error \\
\hline Constant & 651 & 2.9 & 688 & 2.0 & 37 & -0.9 \\
\hline Variable & 676 & 3.9 & 678 & 2.5 & 2 & -1.4 \\
\hline
\end{tabular}


not by participants, $F_{1}(1,11)=2.58, M S E=5,298 ; F_{2}(1$, $12)=7.51, M S E=455, p<.02$. No other main effect or interaction was significant.

Thus, the implicit form-priming effect reported by Meyer (1990) was replicated, but, importantly, only for those sets in which all response words had the same number of syllables. Participants could, for instance, prepare for the response words when they knew that they all began with $/ \mathrm{ma}$, but only if they also knew that all response words had two syllables. When the number of syllables was variable, no preparation for the first syllable was possible. These results show that the metrical structure is involved in advance preparation, as predicted by WEAVER. Furthermore, they imply that the metrical structure is retrieved independently of the words' segments rather than being computed on the basis of segmental information. If the metrical structure were computed on-line on the basis of segmental information, the number of syllables following the one including the shared segments should not matter. By contrast, if the metrical structure is stored and must be retrieved in advance planning, no preparation should be possible if the number of syllables varies. This corresponds to what is empirically obtained.

\section{Experiment 2}

In WEAVER, the metrical structure captures the number of syllables and the stress pattern of words. Experiment 1 had shown that participants needed information about the number of syllables to prepare on the basis of word-initial shared segments. In Experiment 2, we investigated whether knowledge of the stress pattern was also required. We compared the effect of segmental overlap for sets of trisyllabic response words with a constant stress pattern, such as maRIne (navy), maTErie (matter), maLAlse (depression), and maDOna (madonna), to that for sets of trisyllabic words with stress on the second or third syllable, such as maRIne (navy), maTErie (matter), manuSCRIPT (manuscript), and madeLIEF (daisy). ${ }^{3}$ WEAVER predicts an effect of segmental overlap only for sets in which all response words have the same stress pattern.

\section{Method}

Participants. Experiment 2 was conducted with 16 participants.

Materials and design. The stimulus materials consisted of 4 practice sets and 32 experimental sets of 4 word pairs each (see Appendix A). There were 16 homogeneous and 16 heterogeneous sets. In the homogeneous condition, the response words shared the initial syllable $(/ \mathrm{ka} /, / \mathrm{re} /, / \mathrm{ma} /$, or $/ \mathrm{si} /)$, whereas in the heterogeneous condition there was no such overlap. In 8 homogeneous and 8 heterogeneous sets all responses had the same stress pattern, and in the remaining sets the stress pattern varied. Hereafter, we refer to this variable as stress pattern (constant vs. variable). In 4 homogeneous sets with constant stress pattern, primary stress was on the second syllable; in the other 4 homogeneous sets with constant stress pattern, primary stress was on the third syllable. This variable will be called place of stress (second vs. third syllable).

The design differed from that of Experiment 1 in two ways. First, the same prompt-response word pairs were used in sets with constant and variable stress pattern. By contrast, in Experiment 1, different pairs had been tested in sets with constant and variable number of syllables. Second, in the variable sets of Experiment 1, each of the three response words within a variable set had a different number of syllables. By contrast, the variable sets of Experiment 2 included two response words with stress on the second and two with stress on the third syllable. An exhaustive search of the CELEX database revealed that there were not enough suitable words to construct three sets of three words with the same first syllable, one of which was stressed on the second, one on the third, and one on the fourth syllable. Note that the first syllable, which included the shared segments, had to be unstressed because the goal was to investigate whether participants had to know the stress pattern of the entire word, and not only the stress value of the critical first syllable, to prepare for the utterances.

Each of the 32 experimental sets was tested in a separate test block. All participants were tested once on each set. The order of the sets was rotated across participants in a similar way as in Experiment 1. Eight participants (Groups A and B) were first tested on the 16 sets with a variable stress pattern and then on the 16 sets with a constant stress pattem. For the remaining 8 participants (Groups C and D), the order of testing these sets was reversed. For participants of Groups $A$ and $C$, Blocks 1-4 (Part 1 of the experiment), Blocks 5-8 (Part 2), Blocks 17-20 (Part 5), and Blocks 21-24 (Part 6) were homogeneous, and the remaining blocks were heterogeneous. For participants of Groups B and D, the order of homogeneous and heterogeneous blocks was reversed. The 4 participants within each group differed in the order of the four sets within each part of the experiment. Each set was tested once as the first, second, third, and fourth set of a part. In each block, each of the four prompt-response word pairs of the set was tested four times.

\section{Results and Discussion}

The production latencies were submitted to ANOVAs with the crossed variables context (homogeneous vs. heterogeneous), stress pattern (constant vs. variable), place of stress (second vs. third syllable), and fragment $(/ \mathrm{ka} /, / \mathrm{re} /$, $/ \mathrm{ma} /$, or $/ \mathrm{si} /$ ). All variables were tested within participants. Context and stress pattern were tested within items, and the other two variables were tested between items. As Table 3 shows, a strong facilitatory effect from segmental overlap was obtained in the constant sets, whereas the effect was absent in the variable ones. The interaction of context (homogeneous vs. heterogeneous) and stress pattern (constant vs. variable) was significant, $F_{1}(1,12)=11.95, M S E=$ $2,374, p<.005 ; F_{2}(1,24)=20.46, M S E=347, p<.001$. In analyses of simple effects, the effect of context was significant for the constant sets, $F_{1}(1,12)=8.81, M S E=$ $5,740, p<.02 ; F_{2}(1,24)=23.04, M S E=549, p<.001$. However, it was not significant for the variable ones, $F_{1}(1$, 12) $<1, M S E=5,430 ; F_{2}(1,24)<1, M S E=668$. The main effect of context was only significant in the item analysis, $F_{1}(1,12)=2.54, M S E=8,796 ; F_{2}(1,24)=6.43$, $M S E=870, p<.02$. The same was true for the Context $\times$ Stress Pattern $\times$ Fragment interaction, $F_{1}(3,36)=2.02$, $M S E=2,253, p<.12 ; F_{2}(3,24)=3.28, M S E=347, p<$ .04. Finally, there was a main effect of fragment, $F_{1}(3,36)=$ $14.42, M S E=4,558, p<.001, F_{2}(3,24)=3.89, M S E=$

\footnotetext{
${ }^{3}$ The syllable carrying main word stress is capitalized.
} 
Table 3

Mean Production Latencies (in Milliseconds), Error Percentages, and Priming Effects (Diff.) for Experiment 2

\begin{tabular}{|c|c|c|c|c|c|c|}
\hline \multirow{3}{*}{$\begin{array}{l}\text { Stress } \\
\text { pattern }\end{array}$} & \multicolumn{4}{|c|}{ Context } & & \\
\hline & \multicolumn{2}{|c|}{ Homogeneous } & \multicolumn{2}{|c|}{ Heterogeneous } & \multicolumn{2}{|c|}{ Diff. } \\
\hline & $M$ & $\%$ error & $M$ & $\%$ error & $M$ & $\%$ error \\
\hline Constant & 729 & 5.5 & 757 & 4.3 & 28 & -1.2 \\
\hline \multicolumn{7}{|l|}{ Place of stress } \\
\hline 2nd syllable & 703 & 4.2 & 737 & 3.2 & 34 & -1.0 \\
\hline 3rd syllable & 755 & 6.8 & 777 & 5.4 & 22 & -1.4 \\
\hline Variable & 739 & 5.3 & 737 & 3.1 & -2 & -2.2 \\
\hline \multicolumn{7}{|l|}{ Place of stress } \\
\hline 2nd syllable & 722 & 3.7 & 727 & 2.5 & 5 & -1.2 \\
\hline 3rd syllable & 756 & 6.8 & 748 & 3.6 & -8 & -3.2 \\
\hline
\end{tabular}

$4,221, p<.02$, which may be due to differences in the word frequencies of the response words or in the association strength between prompts and response words.

Thus, as predicted, preparation was observed for the metrically constant sets ( 729 vs. $757 \mathrm{~ms})$ but not for the variable sets (739 vs. $737 \mathrm{~ms}$ ). However, WEAVER also predicts that the mean production latencies should be shorter in the homogeneous-constant sets than in the other three types of sets, for which they should not differ. This prediction was not borne out by the data. The nuisance factor appeared to be place of stress. Overall, the words with second-syllable stress were produced faster than those with third-syllable stress: $M \mathrm{~s}=722$ vs. $759 \mathrm{~ms} ; F_{1}(1,12)=$ 48.04, MSE $=3,617, p<.001, F_{2}(1,24)=10.29, M S E=$ $4,221, p<.004$. In the constant sets, the difference between second-syllable and third-syllable stressed words (collapsed across the homogeneous and heterogeneous context) was 46 ms. Surprisingly, when second-syllable and third-syllable stressed words were combined into variable sets, this difference was reduced to $28 \mathrm{~ms}$ because the third-syllable stressed words were produced faster in the variable sets than in the constant sets, whereas the second-syllable stressed words were produced equally fast in both set types. The resulting interaction was significant, $F_{1}(1,12)=5.35$, $M S E=2,001, p<.04 ; F_{2}(1,24)=4.26, M S E=628, p<$ .05 . Thus, the unexpectedly short mean production latencies for the variable condition arose because the responses for the words with third-syllable stress were so fast. As Table 3 shows, for both second-syllable stressed and third-syllable stressed response words, we found a preparation effect only if the stress pattern was the same for all response words within a set. There was no triple interaction between context, stress pattern, and place of stress, $F_{1}(1,12)<1, M S E=$ 1,$302 ; F_{2}(1,24)<1, M S E=347$. However, the constancy effect within the homogeneous condition that was also predicted by WEAVER was observed only for the secondsyllable stressed words and not for the third-syllable stressed words, because of the anomalously fast production of the third-syllable stressed words in variable sets. We do not know why the words with stress on the third syllable behaved as they did. Further testing is needed to make sure that the findings for the items with third-syllable stress in this experiment are anomalous and do not pose difficulty to WEAVER. However, our main hypothesis-that preparation is only possible if the metrical structure is constant-is well supported by the data. Thus, in this important respect, the results of Experiment 2 parallel those of Experiment 1.

Note that the first syllable of the response words of Experiment 2, which included the shared segments, was always unstressed; metrically constant and variable sets differed in whether stress assignment to the following syllables was fixed or variable. Thus, the data show that knowledge of the metrical structure of the entire word was crucial for efficient preparation. WEAVER stipulates that the full metrical representation of a word must be available before the association of segments to positions in the metrical representation can begin. The present data support this assumption. The results also show that the metrical structure is retrieved independently of the segmental structure. If the stress pattern were an integral part of the segmental structure (e.g., coded by diacritics attached to vowels), or if it were computed on the basis of segmental information, a preparation effect for the first syllable should be obtained for words with variable metrical structure, as long as the stress value of the first syllable is constant.

\section{Experiment 3}

The results of Experiments 1 and 2 already suggest that constancy in CV structure is not necessary to observe a preparation effect, because in none of these experiments was this structure identical across response words within homogeneous sets (although one could perhaps argue that the response words in the metrically constant sets were more similar in CV structure than those in metrically variable sets). Results obtained by Meyer $(1990,1991)$ and Roelofs (1996) also showed that preparation effects can be obtained for homogeneous sets with variable CV structures. However, although constancy in CV structure does not appear to be necessary to obtain a facilitatory effect, it is still possible that stronger effects arise for sets with constant than with variable CV structure. This is not predicted by WEAVER, but, as explained in the Introduction, other investigators have argued for an explicit representation of $\mathrm{CV}$ structure. Therefore, Experiment 3 tested whether the size of the preparation effect was affected by the constancy versus the variability of the $\mathrm{CV}$ structure of the response words. We compared the effects of segmental overlap for monosyllabic response sets with a constant CV structure (CCVC), such as bres (breach), bril (glasses), brok (piece), and brug (bridge), to that for sets with variable CV structure, such as brij (porridge; CCVV), brief (letter; CCVVC), bron (source; $C C V C$ ), and brand (fire; CCVCC).

\section{Method}

Participants. The experiment was carried out with 8 participants. Materials. The stimulus materials consisted of 4 practice and 16 experimental sets of four prompt-response word pairs each (see Appendix B). All response words were monosyllabic and began with a consonant cluster. The experimental sets consisted of 8 homogeneous sets, in which the response words shared the onset 
cluster, and 8 heterogeneous sets, in which this was not the case. Meyer (1991) has shown that preparation effects can be obtained when the response words only share the word onset. In 4 homogeneous and 4 heterogeneous sets all response words had the same CV structure (CCVC). The remaining sets included response words that differed in CV structure, one each having a CCVV, CCVVC, CCVC, and CCVCC structure. The design was the same as in Experiment 1, except that there were now 16 experimental blocks and that within each block each prompt-response word pair was tested five times.

\section{Results and Discussion}

Table 4 gives the mean production latencies and the error percentages. Table 4 shows that a priming effect from segmental overlap was obtained for constant and variable sets and that the size of the effect was almost identical for both set types. The data were analyzed with the crossed variables context, $\mathrm{CV}$ structure, and fragment. All variables were tested within participants. Context was tested within items, and the other two variables were tested between items. There were significant main effects of context, $F_{1}(1$, $7)=7.09, M S E=14,099, p<.03, F_{2}(1,24)=85.20$, $M S E=586, p<.001$, and fragment, $F_{1}(3,21)=4.78$, $M S E=3,000, p<.01, F_{2}(3,24)=4.59, M S E=1,561, p<$ .01 . Neither the main effect of CV structure nor any of the interactions involving this variable approached significance.

Thus, the size of the preparation effect was independent of whether the response words had the same or different $\mathrm{CV}$ structures. Our interpretation of this finding is that the metrical structure speakers retrieve does not include a CV tier. We return to the implications of this view in the General Discussion below.

\section{Overview of Experiments 4, 5, and 6}

Experiments 1 and 2 showed that segmental priming effects could only be obtained when the response words had the same metrical structure, that is, the same number of syllables and stress pattern. In contrast, in Experiment 3 segmental priming was found regardless of whether the response words within a set had the same or different $\mathrm{CV}$ structures. This suggests that segments are associated to metrical structures that specify the number of syllables and the stress pattern of the word but not the CV structure. Experiments 4-6 investigated whether priming effects could be obtained from shared metrical structures alone. As we will explain below, WEAVER does not predict such pure metrical priming effects.

Table 4

Mean Production Latencies (in Milliseconds), Error Percentages, and Priming Effects (Diff.) for Experiment 3

\begin{tabular}{|c|c|c|c|c|c|c|}
\hline \multirow{3}{*}{$\begin{array}{c}\mathrm{CV} \\
\text { pattern }\end{array}$} & \multicolumn{4}{|c|}{ Context } & \multirow{2}{*}{\multicolumn{2}{|c|}{ Diff. }} \\
\hline & \multicolumn{2}{|c|}{ Homogeneous } & \multicolumn{2}{|c|}{ Heterogeneous } & & \\
\hline & $M$ & \% error & $M$ & $\%$ error & $M$ & $\%$ error \\
\hline $\begin{array}{l}\text { Constant } \\
\text { Variable }\end{array}$ & $\begin{array}{l}666 \\
657\end{array}$ & $\begin{array}{l}5.6 \\
2.7\end{array}$ & $\begin{array}{l}723 \\
711\end{array}$ & $\begin{array}{l}2.3 \\
3.9\end{array}$ & $\begin{array}{l}57 \\
54\end{array}$ & $\begin{array}{r}-3.3 \\
1.2\end{array}$ \\
\hline
\end{tabular}

Note. $\mathrm{CV}=$ consonant-vowel.
A working assumption implemented in WEAVER is that metrical and segmental spell-out run in parallel and take about the same amount of time. This hypothesis appears plausible given that both processes can start at the same time and both metrical and segmental information must be available before syllabification can begin. Furthermore, it constitutes the simplest parameterization of the model (because there is only one parameter for the duration of both processes).

If metrical and segmental spell-out take about the same amount of time, there should be no priming when segments are shared but the metrical structure is variable. This prediction was confirmed in Experiments 1 and 2. If stages run in parallel, the slowest sets the pace of the whole. In those experiments, facilitation from segmental overlap could have been obtained in the metrically variable sets if metrical spell-out had taken less time than segmental spell-out. For example, if the retrieval of a metrical structure takes $30 \mathrm{~ms}$ and segmental spell-out takes $50 \mathrm{~ms}$, then segmental overlap could yield a facilitatory effect of up to $20 \mathrm{~ms}$. The absence of facilitation in the variable sets excludes the possibility that metrical spell-out is much faster than segmental spell-out.

If (contrary to WEAVER) metrical spell-out is slower than segmental spell-out, metrical priming should be possible. This is the prediction tested in Experiments 4-6. For example, if metrical spell-out takes $50 \mathrm{~ms}$ and segmental spell-out only $30 \mathrm{~ms}$, identity in metrical structure could yield a facilitatory effect of up to $20 \mathrm{~ms}$. Metrical priming effects should also be obtained if (again contrary to WEAVER) metrical spell-out does not run parallel with segmental spell-out but instead precedes it.

The effect of shared metrical structure in the absence of segmental overlap cannot be assessed by comparing the constant and the variable heterogeneous sets of Experiment 1 because this would involve a direct comparison between different items. However, in Experiment 2 the same items were tested in constant and variable sets. In this experiment, there was no facilitatory effect of constant relative to variable stress pattern in the heterogeneous condition. (In fact, a nonsignificant trend in the opposite direction was observed.) Thus, as predicted by WEAVER, no priming was obtained from constant stress pattern alone. Experiments 4-6 tested systematically whether metrical priming in the absence of segmental overlap could be obtained.

\section{Experiment 4}

In Experiment 4, we tested whether a metrical priming effect could be obtained by comparing response latencies for sets of response words with a constant number of syllables, such as majoor (major), sigaar (cigar), and detail (detail), with the response latencies for sets with a variable number of syllables, such as sigaar (cigar), materie (matter), and delirium (delirium).

\section{Method}

Participants. The experiment was carried out with 18 participants. Materials and design. The materials consisted of two practice sets and six experimental sets of three word pairs each. There were 
three different constant and three different variable sets. In the constant condition, all response words within a set had the same number of syllables, including either one, two, or three syllables (see Appendix C). By contrast, each variable set included one mono-, one di-, and one trisyllabic word.

As there were only six different sets, each of them was tested three times within participants such that the entire experiment comprised 18 test blocks. We call this variable with three levels set repetition. In the preceding experiments, each set had only been tested once. The three variable and the three constant sets of Experiment 4 were tested in alternation. Nine participants were first tested on the three variable sets, then on the three constant sets, then on the variable sets again, and so on. For the remaining participants, the order of variable and constant sets was reversed. In each block, each item was tested six times.

\section{Results}

Table 5 gives the mean production latencies and the error percentages. The data were analyzed with the crossed variables number of syllables (constant, variable) and set repetition. The variables were tested within participants and items. Table 5 shows that the production latencies were almost the same for the conditions with the constant and variable number of syllables. The 10 -ms effect of number of syllables was not reliable, $F_{1}(1,17)=5.0, M S E=1,529$, $p<.04 ; F_{2}(1,6)=2.04, M S E=625$. Thus, there was no evidence that the participants could prepare for the response words on the basis of the metrical information provided in the constant sets. They were even slightly slower in these than in the variable sets. The only significant effect was that of set repetition. As one might expect, the mean production latencies decreased across repetitions $(M \mathrm{~s}=733,709$, and $690 \mathrm{~ms}$ for repetitions 1,2 , and 3 , respectively), $F_{1}(2,34)=$ $14.64, M S E=3,445, p<.001 ; F_{2}(2,12)=33.07, M S E=$ $254, p<.001$. There was no interaction between set repetition and number of syllables.

\section{Experiment 5}

In Experiment 5, we tested whether participants could prepare for response words on the basis of information about the stress pattern of trisyllabic response words. Sets with constant stress pattern, such as POdium (stage), MAkelaar (broker), and REgio (region), were compared with sets with

Table 5

Mean Production Latencies (in Milliseconds), Error Percentages, and Priming Effects (Diff.) for Experiments 4,5 , and 6

\begin{tabular}{|c|c|c|c|c|c|c|}
\hline \multirow[b]{3}{*}{ Attribute } & \multicolumn{4}{|c|}{ Metrical structure } & \multirow{2}{*}{\multicolumn{2}{|c|}{ Diff. }} \\
\hline & \multicolumn{2}{|c|}{ Constant } & \multicolumn{2}{|c|}{ Variable } & & \\
\hline & $M$ & $\%$ error & $M$ & $\%$ error & $M$ & $\%$ error \\
\hline No. of syllables & 716 & 3.1 & 706 & 2.7 & -10 & -0.4 \\
\hline Stress pattem & 700 & 2.0 & 699 & 2.3 & -1 & 0.3 \\
\hline CV pattern & 730 & 2.7 & 732 & 3.0 & 2 & 0.3 \\
\hline
\end{tabular}

Note. $\mathrm{CV}=$ consonant-vowel. variable stress pattern, such as POdium, maDOnna (madonna), and resulTAAT (result).

\section{Method}

Participants. The experiment was conducted with 12 participants. Materials and design. The materials consisted of two practice sets and three variable and three constant experimental sets of three word pairs each (see Appendix C). All response words within constant sets were stressed on the same syllable (first, second, or third), whereas the response words within a variable set differed in stress pattern. The design was the same as in Experiment 4.

\section{Results}

Table 5 gives the mean production latencies and the error percentages. The data were analyzed with the crossed variables stress pattern (constant, variable), place of stress (first, second, or third syllable), and set repetition. All variables were tested within participants. Stress pattern and set repetition were tested within items, and place of stress was tested between items. Table 5 shows that the production latencies for the conditions with the constant and variable stress pattern were almost identical, $F_{1}(1,11)<1, M S E=$ 2,$409 ; F_{2}(1,6)<1, M S E=275$. Thus, there was again no evidence for pure metrical priming. The main effect of place of stress (first vs. second vs. third syllable) was significant by participants, but not by items, $F_{1}(2,22)=4.11, M S E=$ $3,155, p<.03 ; F_{2}(2,6)<1, M S E=4,888$. As in Experiment 4, a main effect of set repetition was found $(M \mathrm{~s}=732,690$, and $676 \mathrm{~ms}$ for repetitions 1,2 , and 3, respectively): $F_{1}(2,22)=9.32, M S E=6,388, p<.001$; $F_{2}(2,12)=38.23, M S E=389, p<.001$. There was no interaction between set repetition and stress pattern.

\section{Experiment 6}

In the last experiment, we compared sets with constant CV pattern, such as vlag (flag), spel (game), prik (prick), and bron (source; all CCVC), with sets with a variable $\mathrm{CV}$ pattern, such as prei (leek; CCVV), vloer (floor; CCVVC), bron (source; CCVC), and spons (sponge; CCVCC). This should reveal whether participants could prepare for the responses on the basis of information about the $\mathrm{CV}$ structure of the response words.

\section{Method}

Participants. The experiment was carried out with 8 participants.

Materials and design. The stimulus materials consisted of two practice sets and eight experimental sets of four word pairs each (see Appendix C). There were four different constant and four different variable sets. In the constant condition the response words shared the CV pattern, and in the variable condition they differed in $\mathrm{CV}$ pattern. The four $\mathrm{CV}$ patterns that were used were CCVV, CCVC, CCVVC, and CCVCC. The design was the same as in Experiments 4 and 5, except that there were now eight instead of six experimental blocks, which were tested twice each instead of three times. In each block, each word pair occurred five times. 


\section{Results}

Table 5 gives the mean production latencies and the error percentages. The data were analyzed with the crossed variables $C V$ pattern (constant, variable) and set repetition. The variables were tested within participants and items. Table 5 shows that the production latencies for the conditions with constant and variable $\mathrm{CV}$ pattern were almost identical, $F_{1}(1,7)<1, M S E=2,717 ; F_{2}(1,12)<1, M S E=$ 658. Again, only a main effect of set repetition was obtained ( $M \mathrm{~s}=762$ and $711 \mathrm{~ms}$ for repetitions 1 and 2, respectively): $F_{1}(1,7)=18.18, M S E=2,974, p<.004 ; F_{2}(1,12)=$ $68.73, M S E=393, p<.001$. There was no interaction between set repetition and $C V$ pattern.

The results of Experiments 4, 5, and 6 can be easily summarized: There was no evidence at all for pure metrical priming. Participants could not exploit information about the number of syllables, stress pattern, or CV structure of the response words to prepare for the utterances. As explained above, WEAVER does not predict pure metrical priming effects because metrical and segmental spell-out run in parallel and take about the same amount of time. If metrical spell-out preceded segmental spell-out or took substantially more time, a pure metrical priming effect should have been observed.

\section{Computer Simulations}

In this section, we show by means of computer simulation that WEAVER accounts for the interaction of the effects of shared segments and shared metrical structure observed in Experiments 1 and 2. The simulations involved word-form encoding up to the access to the phonetic syllabary. The mathematical equations for the spreading of activation, the selection, the expectation of the word-form encoding latency, and the parameter values can be found in Roelofs (1992a, 1992b, 1993, 1996, 1997). The parameter values for WEAVER that fit the present data were identical with fits of WEAVER to other data. The simulations compared the effect of segmental overlap for response sets with a constant number of syllables, such as manier, matras, and makreel, with that for sets with a variable number of syllables, such as majoor, materie, and malaria. In WEAVER, the effect of this manipulation is exactly the same as that of comparing constant versus variable stress pattern. Both compare the effects of variable and constant metrical structure. The critical items were embedded in a network that coded the forms of 50 other words randomly selected from the CELEX lexical database. A simulation without embedding produced the same outcomes. Advance knowledge about the form of a response word was simulated by completing the morphological, phonological, and phonetic encoding of the word form as much as possible before the beginning of a trial.

Figure 3 gives the results of the simulations. In Experiment 1, facilitation from segmental overlap was obtained only in metrically constant but not in variable sets. As can be seen, WEAVER produces the same pattern.

As explained above, WEAVER yields no priming effect when the response words share the same number of syllables

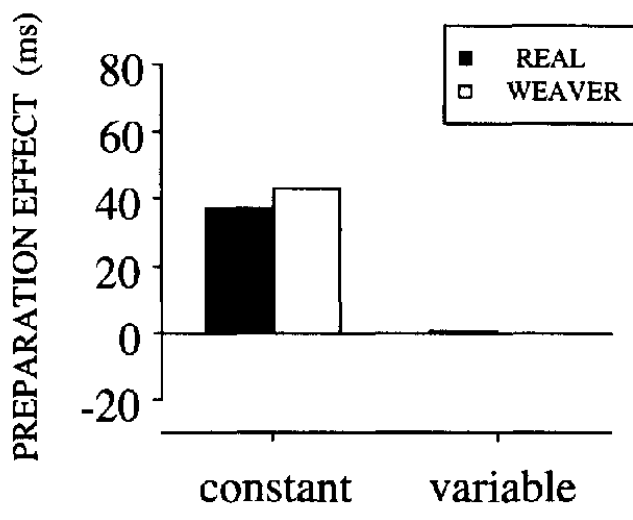

METRICAL STRUCTURE

Figure 3. Mean difference in milliseconds between the production latencies in the homogeneous and the heterogeneous conditions for response sets with constant and variable metrical structure. Real data (Experiment 1) and data simulated by the word-form encoding by activation and verification (WEAVER) model.

or stress pattern but no segments. This is because metrical and segmental spell-out run in parallel and take approximately the same amount of time.

\section{General Discussion}

In Experiments 1 and 2, implicit form-priming effectsshorter production latencies in homogeneous than in heterogeneous sets-were obtained for metrically constant but not for variable sets. The participants apparently needed information about the number of syllables and the stress pattern of the response words to prepare for the utterances on the basis of recurring word-initial segments. These results support the assumption that a metrical structure encoding number of syllables and stress pattern is involved in preparing for an utterance.

In WEAVER, the metrical structure of a word is retrieved independently of its segments. The interaction of the effects of segmental overlap and shared metrical structure in Experiments 1 and 2 may appear to be at variance with this claim. However, it is important to note that the metrical variables manipulated in these experiments did not pertain to the critical syllable, that is, the syllable including the shared segments. In Experiment 1, the critical syllable was the first syllable of the response words, and constant and variable sets differed in whether just one syllable or a variable number of other syllables followed. Similarly, in Experiment 2 , the critical syllable was always unstressed, and constant and variable sets differed in whether the stress pattern of the following syllables was fixed or variable. It is this dissociation of the planning spans at the metrical and segmental level that supports our claim that the two types of representations are stored and retrieved independently of each other. If metrical and segmental information were part of the same representation-if, for instance, the stress pattern were represented in diacritics attached to vowels-there would be no reason why speakers would have to know whether 
primary stress was on the second or third syllable to prepare for the first. Similarly, if speakers generated the stress pattern on the basis of segmental information, there would be no reason why segmental retrieval could be primed only when the stress pattern was constant.

In Experiments 4 and 5, participants could not produce the response words any faster when their number of syllables or stress pattern were constant than when they were variable. In other words, no metrical priming effects in the absence of segmental overlap were obtained. The absence of these effects does not, however, refute our claim that participants retrieved a metrical representation. (Nor does the absence of segmental priming effects in the metrically variable sets of Experiments 1 and 2 refute the claim that there is an independent segmental representation.) The absence of pure metrical priming is, in fact, predicted by WEAVER and is due to the timing of segmental and metrical spell-out. As explained above, in WEAVER these processes run in parallel and normally take about the same amount of time. Speeding up one of these processes will not reduce production latencies because the other process, running at its usual, slower speed, must also be completed before the results of the two processes can be combined and a response can be made.

Thus, the results confirm our hypotheses about the time course of word-form encoding, in particular the assumption that segmental and metrical spell-out are parallel processes of approximately equal duration. If these processes began at the same time, but differed greatly in duration, a "pure" priming effect should have been obtained for the slower process, that is, either for segmental or for metrical spell-out. If metrical retrieval preceded segmental spell-out, metrical priming effects should have been obtained in Experiments 4 and 5. Conversely, if segmental spell-out were carried out first, segmental priming effects should have been found in the variable sets of Experiments 1 and 2 .

Our model of word-form encoding differs from most others in the content of the metrical representation. We found that participants had to know the number of syllables and the stress pattern of the response words to prepare efficiently in the segmentally homogeneous condition, but we did not obtain any evidence that they also had to know the CV structure of the response words. A parsimonious account of these findings is that metrical representations include information about syllable number and stress but not about CV structure.

Obviously, the properties of the metrical representation must be further studied. Our experiments showed that preparation for the response words was only possible if the participants knew the number of syllables and the stress pattern of the responses words. These metrical properties are transparently captured in the metrical representation we propose in Figure 2. However, the metrical representations proposed in phonological theory often look quite different (e.g., Goldsmith, 1990). For instance, syllables are often taken to be grouped into phonological feet, and feet into phonological words. Phonological words differing in number of syllables and stress pattern will also differ in foot structure. Thus, the effects we ascribe to number of syllables and stress pattern could also be effects of foot structure.
We have argued that CV structure is not part of the stored metrical representation. Some linguists have proposed generic timing slots ( $X$ slots) instead of consonantal and vocalic positions (see Goldsmith, 1990, and Kenstowicz, 1994, for review and discussion). Our materials were constructed such that constancy of CV structure entailed a constant number of $\mathrm{X}$ slots, and variability of $\mathrm{CV}$ structure entailed a variable number of $X$ slots. Therefore, our results permit us to conclude that neither $\mathrm{CV}$ structure nor the number of $\mathrm{X}$ slots is represented as part of the metrical representation.

Similarly, our results rule out that the division of syllables into onset, nucleus, and coda is part of the metrical representation. This is because in our sets with constant CV structure, all response words included an onset, a nucleus, and a coda, whereas in sets with variable CV structure, the coda could be absent. However, there is strong evidence from word-game studies (e.g., Treiman, 1983, 1986) for the psychological reality of the syllable constituents onset and rhyme (encompassing nucleus and coda). All targets in the metrically constant and variable conditions of our experiments included both of these syllable constituents. Thus, our data do not exclude the possibility that the parsing of syllables into onsets and rhymes is specified in the metrical representation. However, the word-game studies have shown that the coherence of syllable constituents is a matter of degree and that it depends, in part, on properties of the segments realizing them (e.g., Treiman, 1984; Treiman, Gross, \& Cwikiel-Glavin, 1992; Treiman \& Zukowski, 1990). This suggests that syllable constituents are groups of segments rather than abstract syllable positions. Onsets and rhymes are probably formed when segments are associated to syllables.

Our hypothesis that the stored metrical representation does not include subsyllabic positions has important processing implications. In some models, frames with labeled positions are invoked as ordering devices. For instance, in Dell's (1986) model, the segments of a syllable are activated in parallel and are ordered by association to ordered syllable positions. This presupposes that there are labeled syllableinternal positions and that segments are marked with respect to the positions they may take. In Shattuck-Hufnagel's (1979, 1983) model, segments are likewise ordered by association to labeled syllable-internal positions. In other models (e.g., Dell, 1988, and Meijer, 1994), frames govern how many or which types of segments (consonants or vowels), or both, must be retrieved. Clearly, the metrical structure we propose here cannot fulfill any of these functions because it does not include positions for individual segments. The association of segments to syllables is purely a process of linking separate informational tiers.

How can a model in which the metrical representation does not include the CV structure account for the evidence for such a representation mentioned in the Introduction? Our general answer is that CV structure is captured in ways other than as part of the metrical representation. We assume that information about the phonological features of a word's segments, including their consonantal or vocalic character, becomes available during segmental spell-out. This assump- 
tion is supported by the very robust result of speech-error analyses that the segments interacting in sound errors share, on average, more features than predicted on the basis of a chance estimate (Shattuck-Hufnagel, 1983; ShattuckHufnagel \& Klatt, 1979). Most importantly, vowels almost exclusively replace other vowels and consonants other consonants. Thus, segments have a strong preference to interact with segments specified in the same way as consonantal or vocalic. In addition to this empirical motivation, there is a theoretical reason to assume that phonological features are represented: In WEAVER, the retrieved string of segments must be syllabified by using the syllabification rules of the language, and these rules refer to the segments' phonological features. Thus, some of the observed effects of similarity in CV structure can be viewed as effects of featural similarity. In addition, effects of $\mathrm{CV}$ structure can arise because the same or similar rules are applied during the syllabification process. Syllables with identical CV structure are likely to be generated by using the same syllabification rules. Finally, words are phonetically encoded in WEAVER by selecting syllable-program nodes. The addresses for these nodes include specifications of the number and types of segments and their order. The syllable [wa], for instance, is selected when one prevocalic consonant (labeled on [onset] in Figure 2) and a vowel ( $n u$ [nucleus]) are activated, and the syllable [tor] is selected when one prevocalic consonant, a vowel, and a postvocalic consonant (co [coda]) are active. Thus, CV structure is represented in the addresses to syllable-program nodes. In summary, effects of CV structure can arise without such a structure being part of the metrical representation.

Because CV structure is captured in our model (albeit not as part of the metrical representation), the reported effects of CV structure can be accounted for. Sevald et al. (1995) found that participants could pronounce more pairs of a mono- and a disyllabic target within a given response period when the monosyllable and the first syllable of the disyllabic target had the same CV structure (as in kul par-fen) than when their CV structure differed (as in kult par-fen). No further facilitation was obtained when the critical syllables consisted of the same segments (as in par par-fen). This suggests that the facilitatory effect had a fairly abstract basis and perhaps arose because the same routines of syllabification were applied for the two syllables. The CV priming effect obtained by Meijer $(1994,1996)$ may have the same basis. Alternatively, the facilitatory effect could arise because primes and targets with the same $\mathrm{CV}$ structure are similar in their phonological features, or because they activate syllable-program nodes with similar addresses.

Finally, in WEAVER, most sound errors arise during the selection of syllable programs. An error such as corcical instead of cortical occurs if the syllable [ki] is selected instead of the syllable [ti]. Syllables with the same CV structure have addresses with the same structure (e.g., one consonant followed by one vowel) and may therefore be more likely to be confused with each other than syllables differing in CV structure. This may lead to the reported effects of CV structure on sound errors. For instance, Stemberger (1990) found that onset errors, such as life can be a lame instead of life can be a game preferentially involve syllables with the same number of coda consonants. The reason for this may be that such syllables are more similar in the structure of their addresses than syllables differing in the number of coda consonants. The syllable position constraint on sound errors can probably be explained in a similar way: There are more errors in which a segment moves from a source syllable to the corresponding position in a new syllable than to a new syllable position because the source syllable and the resulting syllable are most similar when the moved segment maintains its original syllable position.

\section{Conclusion}

Our experiments show that the generation of a word form involves the retrieval of an abstract metrical representation capturing the number of syllables and the stress pattern of the word (or perhaps other types of metrical information, such as foot structure, from which these metrical properties can be derived). Metrical and segmental spell-out appear to run in parallel and take about the same amount of time. The experiments did not provide any evidence that the CV structure, the number of timing slots, or the syllable constituents onset, nucleus, and coda are part of the metrical representation. However, as we discussed above, information about the $\mathrm{CV}$ structure becomes available during segmental spell-out.

In all experiments, we used the implicit form-priming paradigm. Obviously, our experimental task differed in a number of ways from ordinary speech production. People rarely say the same three or five words over and over again, and they cannot normally predict how the next word to be uttered will begin or how many syllables it will include. Yet, the preparation effects in implicit form-priming experiments show very systematic patterns; participants can exploit certain types of information, whereas other types are utterly useless. A natural account of these patterns is to relate them to the way speech is normally planned. Thus, we assume that the reason preparation effects were obtained only when both segmental and metrical information was provided is that in the planning of normal speech, these two types of information are retrieved independently but in parallel.

\section{References}

Baayen, R. H., Piepenbrock, R., \& van Rijn, H. (1993). The CELEX lexical database [CD-ROM]. Linguistic Data Consortium, University of Pennsylvania, Philadelphia.

Beland, R., Caplan, D., \& Nespoulous, J. -L. (1990). The role of abstract phonological representations in word production: Evidence from phonemic paraphasia. Joumal of Neurolinguistics, 5, 125-164.

Berg, T. (1991). Phonological processing in a syllable-timed language with pre-final stress: Evidence from Spanish speech error data. Language and Cognitive Processes, 6, 265-301.

Booij, G. E. (1995). The phonology of Dutch. Oxford, England: Clarendon Press.

Butterworth, B. (1989). Lexical access in speech production. In W. Marslen-Wilson (Ed.), Lexical representation and process (pp. 108-135). Cambridge, MA: MIT Press.

Caplan, D. (1992). Language: Structure, processing, and disonders. Cambridge, MA: MTT Press. 
Clements, G. N., \& Keyser, S. J. (1983). CV Phonology. (Linguistic Inquiries Monographs Series No. 9). Cambridge, MA: MIT Press.

Cutler, A. (1980a). Errors of stress and intonation. In V. A. Fromkin (Ed.), Errors in linguistic performance. Slips of the tongue, ear, pen, and hand (pp. 67-80). New York: Academic Press.

Cutler, A. (19806). Syllable omission errors and isochrony. In H. W. Dechert \& M. Raupach (Eds.), Temporal variables in speech (pp. 183-190). The Hague, the Netherlands: Mouton.

Dell, G. S. (1986). A spreading-activation theory of retrieval in sentence production. Psychological Review, 93, 283-321.

Dell, G. S. (1988). The retrieval of phonological forms in production: Tests of predictions from a connectionist model. Journal of Memory and Language, 27, 124-142.

Dell, G. S., Juliano, C., \& Govindjee, A. (1993). Structure and content in language production: A theory of frame constraints in phonological speech errors. Cognitive Science, 17, 149-195.

Fromkin, V. A. (1973). Speech errors as linguistic evidence. The Hague, The Netherlands: Mouton.

García-Albea, J. E., del Viso, S., \& Igoa, J. M. (1989). Movement errors and levels of processing in sentence production. Journal of Psycholinguistic Research, 18, 145-161.

Garrett, M. F. (1975). The analysis of sentence production. In G. H. Bower (Ed.), The psychology of learning and motivation (pp. 133-177). New York: Academic Press.

Garrett, M. F. (1980). Levels of processing in sentence production. In B. Butterworth (Ed.), Language production: Vol. 1. Speech and talk (pp. 177-210). New York: Academic Press.

Goldsmith, J. (1990). Autosegmental and metrical phonology. Cambridge, MA: Basil Blackwell.

Kempen, G., \& Hoenkamp, E. (1987). An incremental procedural grammar for sentence formulation. Cognitive Science, 11, 201-258.

Kempen, G., \& Huijbers, P. (1983). The lexicalization process in sentence production and naming: Indirect election of words. Cognition, 14, 185-209.

Kenstowicz, M. (1994). Phonology in generative grammar. Oxford, UK: Blackwell.

Levelt, W. J. M. (1989). Speaking: From intention to articulation. Cambridge, MA: MIT Press.

Levelt, W. J. M. (1992). Accessing words in speech production: Stages, processes and representations. Cognition, 42, 1-22.

Levelt, W. J. M., \& Wheeldon, L. (1994). Do speakers have access to a mental syllabary? Cognition, 50, 239-269.

McCarthy, J. (1981). A prosodic theory of nonconcatenative morphology. Linguistic Inquiry, 12, 373-418.

Meijer, P. J. A. (1994). Phonological encoding: The role of suprasegmental structures. Unpublished doctoral dissertation, University of Nijmegen, The Netherlands.

Meijer, P. J. A. (1996). Suprasegmental structures in phonological encoding: The CV structure. Journal of Memory and Language, $35,840-853$.

Meyer, A. S. (1990). The time course of phonological encoding in language production: The encoding of successive syllables of a word. Journal of Memory and Language, 29, 524-545.

Meyer, A. S. (1991). The time course of phonological encoding in language production: The phonological encoding inside a syllable. Joumal of Memory and Language, 30, 69-89.

Meyer, A. S. (1992). Investigation of phonological encoding through speech error analyses: Achievements, limitations, and alternatives. Cognition, 42, 181-211.

Meyer, A. S. (1996). Lexical access in phrase and sentence production: Results from picture-word interference experiments. Journal of Memory and Language, 35, 477-496.

Roelofs, A. (1992a). Lemma retrieval in speaking: A theory, computer simulations, and empirical data. (NICI Tech. Rep. No. 92-08). Nijmegen, the Netherlands: University of Nijmegen.
Roelofs, A. (1992b). A spreading-activation theory of lemma retrieval in speaking. Cognition, 42, 107-142.

Roelofs, A. (1993). Testing a non-decompositional theory of lemma retrieval in speaking: Retrieval of verbs. Cognition, 47, 59-87.

Roelofs, A. (1994). On-line versus off-line priming of word-form encoding in spoken word production. In A. Ram \& K. Eiselt (Eds.), Proceedings of the Sixteenth Annual Conference of the Cognitive Science Society (pp. 772-777). Hillsdale, NJ: LEA.

Roelofs, A. (1996). Serial order in planning the production of successive morphemes of a word. Journal of Memory and Language, 35, 854-876.

Roelofs, A. (1997). The WEAVER model of word-form encoding in speech production. Cognition, 64, 249-284.

Roelofs, A. (in press). Rightward incrementality in encoding simple phrasal forms in speech production: Verb-particle combinations. Journal of Experimental Psychology: Learning, Memory, and Cognition

Rosenbaum, D. A., Kenny, S., \& Derr, M. A. (1983). Hierarchical control of rapid movement sequences. Journal of Experimental Psychology: Human Perception and Performance, 9, 86-102.

Sevald, C. A., Dell, G., \& Cole, J. S. (1995). Syllable structure in speech production: Are syllables chunks or schemas? Journal of Memory and Language, 34, 807-820.

Shattuck-Hufnagel, S. (1979). Speech errors as evidence for a serial-ordering mechanism in sentence production. In W. E. Cooper \& E. C. T. Walker (Eds.), Sentence processing: Psycholinguistic studies presented to Merrill Garrett (pp. 295-342). Hillsdale, NJ: Erlbaum.

Shattuck-Hufnagel, S. (1983). Sublexical units and suprasegmental structure in speech production planning. In P. F. MacNeilage (Ed.), The production of speech (pp. 109-136). New York: Springer.

Shattuck-Hufnagel, S. (1986). The representation of phonological information during speech production planning: Evidence from vowel errors in spontaneous speech. Phonology Yearbook, 3, 117-149.

Shattuck-Hufnagel, S. (1987). The role of word-onset consonants in speech production planning. New evidence from speech error patterns. In E. Keller \& M. Gopnik (Eds.), Motor and sensory processes of language (pp. 17-51). Hillsdale, NJ: Erlbaum.

Shattuck-Hufnagel, S. (1992). The role of word structure in segmental serial ordering. Cognition, 42, 213-259.

Shattuck-Hufnagel, S., \& Klatt, D. H. (1979). The limited use of distinctive features and markedness in speech production: Evidence from speech error data. Journal of Verbal Learning and Verbal Behavior, 18, 41-55.

Stemberger, J. P. (1984). Length as a suprasegmental: Evidence from speech errors. Language, 60, 895-913.

Stemberger, J. P. (1990). Wordshape errors in language production. Cognition, 35, 123- 157.

Treiman, R. (1983). The structure of spoken syllables: Evidence from novel word games. Cognition, 15, 49-74.

Treiman, R. (1984). On the status of final consonant clusters in English syllables. Journal of Verbal Learning and Verbal Behavior, 23, 343-356.

Treiman, R. (1986). The division between onsets and rimes in English syllables. Journal of Memory and Language, 25, 476-491.

Treiman, R, Gross, J., \& Cwikiel-Glavin, A. (1992). The syllabification of $/ \mathrm{s} /$ clusters in English. Journal of Phonetics, 20 , 383-402.

Treiman, R., \& Zukowski, A. (1990). Toward an understanding of English syllabification. Joumal of Memory and Language, 29, 66-85. 


\section{Appendix A}

\section{Response Sets of Experiment 2}

Stress pattern: constant; context: homogeneous; place of stress: second syllable

Set 1: karakter, kanarie, kazerne, kabouter (character, canary, barrack, gnome)

Set 2: religie, reclame, revolte, regressie (religion, commercial, revolt, regression)

Set 3: marine, materie, malaise, madonna (navy, matter, depression, madonna)

Set 4: cynisme, sirene, cilinder, synode (cynicism, siren, cylinder, synod)

Stress pattern: constant; context: homogeneous; place of stress: third syllable

Set 5: karabijn, karavaan, kabeljauw, kabinet (carbine, caravan, codfish, cabinet)

Set 6: republiek, reservoir, resultaat, regisseur (republic, reservoir, result, director)

Set 7: manuscript, madelief, machinist, makelij (manuscript, daisy, engineer, making)

Set 8: sigaret, symmetrie, silhouet, synoniem (cigarette, symmetry, silhouette, synonym)

Stress pattern: constant; context: heterogeneous; place of stress: second syllable

Set 9: karakter, religie, marine, cynisme

Set 10: kanarie, reclame, materie, sirene

Set 11: kazerne, revolte, malaise, cilinder

Set 12: kabouter, regressie, madonna, synode

Stress pattern: constant; context: heterogeneous; place of stress: third syllable

Set 13: karabijn, republiek, manuscript, sigaret

Set 14: karavaan, reservoir, madelief, symmetrie

Set 15: kabeljauw, resultaat, machinist, silhouet

Set 16: kabinet, regisseur, makelij, synoniem

Stress pattern: variable; context: homogeneous

Set 17: karakter, kanarie, karabijn, karavaan

Set 18: religie, reclame, republiek, reservoir

Set 19: marine, materie, manuscript, madelief

Set 20: cynisme, sirene, sigaret, symmetrie

Set 21: kazerne, kabouter, kabeljauw, kabinet

Set 22: revolte, regressie, resultaat, regisseur

Set 23: malaise, madonna, machinist, makelij

Set 24: cilinder, synode, silhouet, synoniem

Stress pattern: variable; context: heterogeneous

Set 25: karakter, reclame, manuscript, symmetrie

Set 26: kanarie, religie, madelief, sigaret

Set 27: karabijn, reservoir, marine, sirene

Set 28: karavaan, republiek, materie, cynisme

Set 29: kazerne, regressie, machinist, synoniem

Set 30: kabouter, revolte, makelij, silhouet

Set 31: kabeljauw, regisseur, malaise, synode

Set 32: kabinet, resultaat, madonna, cilinder 


\section{Appendix B}

\section{Response Sets of Experiment 3}

CV pattern: constant (CCVC); context: homogeneous

Set 1: bres, bril, brok, brug

(breach, glasses, piece, bridge)

Set 2: klip, klem, klas, klok

(rock, trap, class, clock)

Set 3: spar, spot, spek, spin

(pine, spot, bacon, spider)

Set 4: prof, pret, prak, prul (prof, fun, mash, trash)

CV pattern: constant (CCVC); context: heterogeneous

Set 5: prak, bres, klip, spot

Set 6: spek, prul, bril, klok

Set 7: klem, spar, prof, brug

Set 8: brok, klas, spin, pret

CV pattern: variable (CCVV, CCVVC, CCVC, or CCVCC); context: homogeneous

Set 9: brij, brief, bron, brand

(mush, letter, well, fire)

Set 10: klei, kluif, klap, klink

(clay, bone, blow, latch)

Set 11: spa, spier, spel, spons

(mineral water, muscle, game, sponge)

Set 12: prei, proef, prik, prent (leek, test, injection, picture)

CV pattern: variable (CCVV, CCVVC, CCVC, or CCVCC); context: heterogeneous Set 13: prei, spier, bron, klink

Set 14: spa, brief, klap, prent

Set 15: klei, proef, brand, spel

Set 16: brij, kluif, prik, spons 


\section{Appendix C}

\section{Response Sets of Experiments 4, 5, and 6}

\section{Experiment 4}

Number of syllables: constant

Set 1: majoor, sigaar, detail (major, cigar, detail)

Set 2: sirene, devotie, materie (siren, devotion, matter)

Set 3: delirium, malaria, Siberie (delirium, malaria, Siberia)

Number of syllables: variable

Set 4: sigaar, materie, delirium

Set 5: devotie, Siberie, majoor

Set 6: malaria, detail, sirene

Experiment 5

Stress pattern: constant

Set 1: makelaar, podium, regio (broker, stage, region)

Set 2: madonna, politie, reclame (madonna, police, commercial)

Set 3: maniak, poëzie, resultaat

Stress pattern: variable (maniac, poetry, result)

Set 4: makelaar, politie, resultaat

Set 5: podium, reclame, maniak

Set 6: regio, madonna, poëzie

Experiment 6

CV structure: constant

Set 1: brie, vlo, spa, prei (Brie cheese, flea, mineral water, leek)

Set 2: vlag, spel, prik, bron (flag, game, injection, well)

Set 3: spook, prijs, brief, vloer (ghost, prize, letter, floor)

Set 4: prent, brand, vlucht, spons (picture, fire, flight, sponge)

CV structure: variable

Set 5: brie, vlag, spook, prent

Set 6: spel, prijs, brand, vlo

Set 7: brief, vlucht, spa, prik

Set 8: spons, prei, bron, vloer 